artigo ] ANA PAULA C. DE MIRANDA | LETICIA M. CASOTTI | LEANDRO P. CHEVITARESE
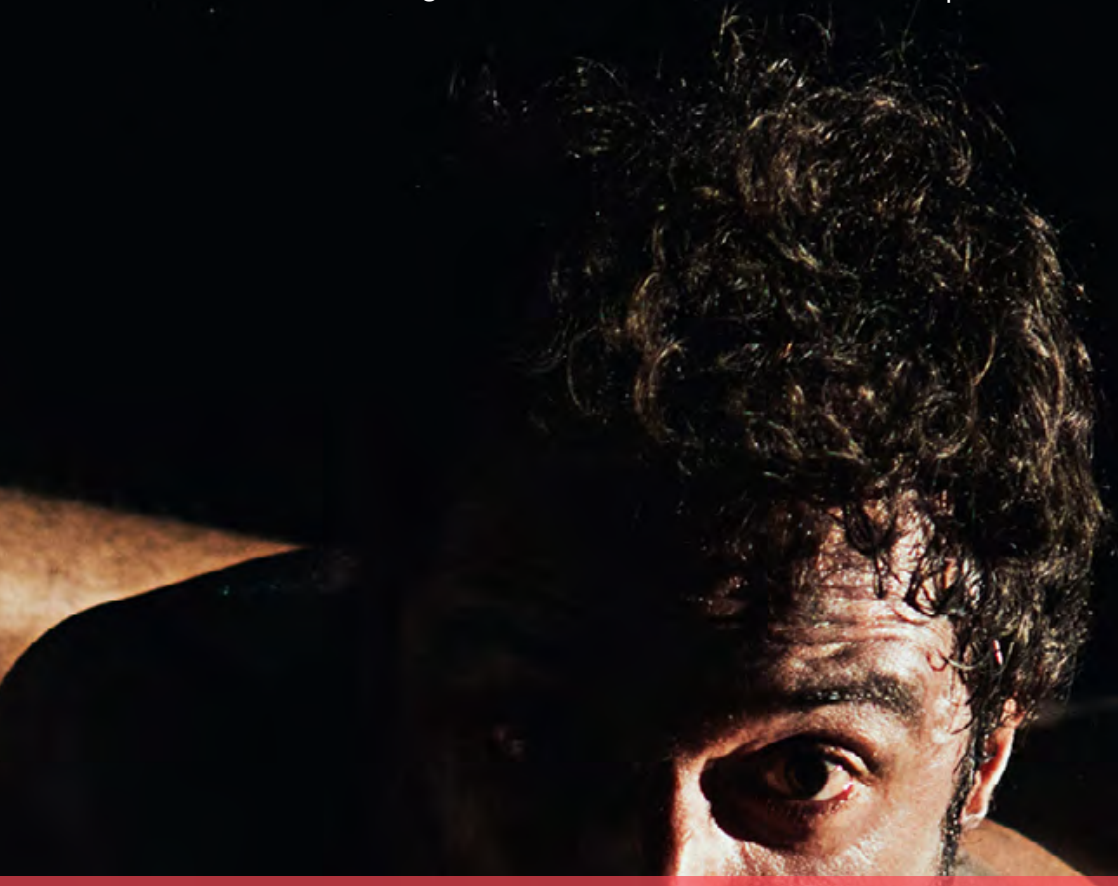

\title{
Saia de homem como discurso de poder
}

\author{
Man's skirt as a discourse of power
}


ANA PAULA C. DE MIRANDA ${ }^{1}$

ORCID: https://orcid.org/0000-0002-0605-4144

\section{LETICIA M. CASOTTI}

ORCID: https://orcid.org/0000-0001-7718-5072

\section{LEANDRO P. CHEVITARESE ${ }^{3}$}

ORCID: https://orcid.org/0000-0001-9599-7496

[resumo] 0 tema desse artigo é o consumo de moda e sua análise é de abordagem interpretativista. 0 objetivo desse estudo foi analisar o discurso de moda a partir do diálogo teórico com o discurso de poder de Foucault e a sociologia do desvio de Becker (2008). 0 percurso metodológico foi a realização de entrevistas em profundidade seguidas de análise de discurso, bem como captação e análise de imagens. Foram entrevistados (entrevistas narrativas) e fotografados (análise da imagem) 20 homens que usam saia no seu cotidiano. Os resultados encontrados discutem sobre o uso da saia por esses homens como discurso de poder que busca a normalização do comportamento visto como desviante pelo empreendedor moral e, por conseguinte, objetiva obter a escolha de identidade de moda livre do julgamento social.

\section{[palavras-chave] Moda. Consumo. Filosofia. Gênero. Cultura.}

[abstract] The subject of this article is fashion consumption, analyzed under an interpretative approach. The goal of the study was to analyze the fashion discourse in a theoretical dialogue with Foucault's discourse of power and Becker's sociology of deviance. The methodological course was based on in-depth interviews, followed by speech analysis as well as the capture and analysis of images. Twenty men who wear skirts in their everyday life were interviewed (narrative interviews) and photographed (image analysis). The results found a discourse about the use of skirts by these men as a power discourse which seeks the normalization of this behavior, seen as deviant by the moral entrepreneur, therefore aiming to obtain a choice of fashion identity unattached to social judgment.

[keywords] Fashion. Consumption. Philosophy. Gender. Culture.

Recebido em: 29-01-2018.

Aprovado em: 05-04-2018.

\footnotetext{
1 Pós-doutorado no Instituto Coppead de Administração (UFRJ). Professora associada do Núcleo de Design e Comunicação da UFPE. E-mail: anapaula.miranda@ufpe.br. Lattes: http://lattes.cnpq.br/5061912856624094.

2 Doutora em Engenharia de Produção pela COPPE (UFRJ). Professora associada do Instituto Coppead de Administração (UFRJ). E-mail: leticia@coppead.ufrj.br. Lattes: http://lattes.cnpq.br/0464268640054997.

3 Doutor em Filosofia pela PUC-RJ. Professor adjunto de filosofia na UFRJ no Departamento de Educação e Sociedade. E-mail: leandrochevitarese@yahoo.com. Lattes: http://Lattes.cnpq.br/3068706676553943.
} 


\section{Introdução}

Em tempos pós-modernos muito se tem falado sobre a dignidade da pessoa humana, o que nos leva a certas reflexões filosóficas como a da liberdade de ação. Estas reflexões nos levam para o campo de estudo da filosofia e, mais especificamente, o da Estética, que não se refere apenas à aparência, como se convencionou, mas a como essa aparência afeta os sentidos. A estética é a reação dos sentidos em relação aos objetos.

Essa discussão sempre foi importante em qualquer momento histórico e não seria diferente no contexto atual, quando as discussões sobre identidade e estética de gênero já aparecem consolidadas em ações de consumo e ofertas de mercado. No caso desse estudo vamos focar na indústria da moda e na aparência estética do que se convencionou chamar de "agênero", o que significa sem gênero ou que não pertence ou é especifico a um determinado gênero.

0 estudo é de abordagem interpretativista; por meio dele foram analisados os discursos dos consumidores após transcrição de suas falas, que foram coletadas por meio de entrevistas em profundidade e da análise das imagens desses homens captadas quando foram abordados pela pesquisadora usando saia em lugares públicos.

Para o diálogo teórico usaremos os estudos de Foucault e relacionaremos com os estudos sobre a sociologia do desvio de Becker (2008). É interessante observar que não vamos estudar a socialização sob o ponto de vista de processo no qual os indivíduos aprendem a viver e a se comportar efetivamente com outras pessoas, mas a ruptura com esse processo. 0 ponto central não é o modo pelo qual a pessoa se integra na sociedade ou se marginaliza, mas como o indivíduo se coloca como agente de transformação dessa sociedade. 0 objetivo do estudo é compreender o consumo de moda, no caso a saia para homem, como forma de estabelecer discursos de transgressão e como este discurso é construído e materializado.

A pesquisa se apoia nos estudos da sociologia do desvio de Becker (2008) que considera a transgressão a essência do comportamento na qual residem as suas mudanças e, logo, a lógica da moda. As regras sociais que definem comportamentos apropriados também localizam pessoas que, não vivendo de acordo com essas regras, são caracterizadas como desviantes, marginais ou divergentes. A transgressão pode estar associada ao não cumprimento de leis que usam o poder de polícia do Estado para se impor ou a outros comportamentos informais e estabelecidos pela cultura e pela tradição. Homens que usam saia se desviaram das regras de grupo ou das regras culturais de gênero e sofrem processos de julgamento na visão de senso comum, ao mesmo tempo que no sistema da moda são vistos como inovadores, aqueles que dão início a um novo comportamento (SIMMEL,1904; BLUMER, 1969).

\section{Saberes e relações de poder: diálogos com Foucault e Becker}

Segundo Foucault (1994c), os saberes que são construídos socialmente por meio de uma rede de discursos advindos das mais variadas fontes (tal como a psicologia, a sociologia, a psiquiatria, a economia, a religião, a medicina etc.) e passam a ocupar o lugar de "verdade", estabelecem mecanismos de coerção sobre os corpos. Desta dinâmica saber-poder surge a produção de subjetividades adequadas ao padrão de "normalidade" então estabelecido. A 
construção de "corpos úteis e dóceis" (FOUCAULT, 1975) não pode prescindir de uma tecnologia de poder que opera pela vigilância e pela punição, disciplinarizando os corpos. Pela concepção foucaultiana de uma microfísica do poder, pode-se dizer que o indivíduo é um efeito do poder, mas também é seu intermediário, pois o poder transita pelos indivíduos que ele constituiu. De forma que o indivíduo tanto pode sofrer sua ação, sendo assujeitado pelas relações de poder, quanto pode ser agente destas mesmas relações de poder (FOUCAULT, 1994a).

Foucault apresenta a disciplina enquanto tentativa de reger a multiplicidade que é própria à condição humana, evitando a singularização; deste modo os indivíduos são vigiados, treinados, utilizados, eventualmente punidos, ou seja, a dinâmica das relações de poder massifica e padroniza a existência. Foucault descreveu vários processos de disciplinarização dos corpos em diferentes instituições, demonstrando que a principal característica delas é a disciplina corporal.

Controlar o sexo, por exemplo, passa por controlar os discursos e as práticas, o dito e o não dito, seja pelo mutismo sobre o assunto que de tanto calar-se impõe o silêncio e, por fim, a censura, seja pela proliferação de discursos sobre o sexo, rejeitando certas formas de comportamento sexual ou estimulando determinada forma de sexualidade (FOUCAULT, 1977). A construção de um padrão de "normalidade" sexual constitui-se como um investimento em gerenciar ações, movimentos, gestos, olhares, palavras, silêncios - o que certamente inclui também a determinação de padrão de vestimenta para o corpo tomado como "normal". Para Foucault, o poder é vivenciado cotidianamente no modo como as pessoas se relacionam diariamente; são relações de poder que definem um molde de comportamento. A possibilidade de estabelecer formas de resistência aos padrões de normalização social depende do exercício de práticas de reinvenção de si mesmo, que se relacionam com aquilo que Foucault (2001) investigou como as práticas de "cuidado de si" presentes na antiguidade greco-romana. As formas de resistência dos indivíduos frente aos processos de subjetivação poderiam caminhar na direção de uma ética-estética da vida, ressignificando o sentido de liberdade (FOUCAULT, 1994b). Tal proposta depende da produção de novos saberes que possibilitem novas relações de poder, tensionando os padrões de normalização vigentes. No presente trabalho, consideramos que a análise da ação do "desviante homem de saia" oportuniza investigar um modo de produzir-se diferenciadamente em relação ao padrão dominante de comportamento, que poderia ser compreendido como uma forma de "resistência" no sentido apresentado por Foucault (1994a).

Becker (2008) fala que a criação de regras e a imposição de regras que levam às punições pelo seu descumprimento podem acontecer desde o constrangimento público até a casos extremos, como espancamento e morte. A Teoria da Rotulação Reconsiderada de Becker faz relações com o interacionismo simbólico e dialoga com os estudos de Goffman (1988), Mead (1934) e Blumer (1969) para propor uma abordagem interacionista do desvio. 0 desvio é a reação a uma imposição de definições a partir de situações, atos e pessoas e legitimado por um poder ou por quem é poderoso. Os estudos de Becker se conectam com outros estudos das ciências sociais, como os do antropólogo brasileiro Gilberto Velho (1976, 2003), pois ambos parecem concordar que ser desviante é estar sob estigma, ser desviante é estar sob acusação, o que proporciona uma abordagem foucaultiana para o mapeamento da 
verdade desse desviante como identidade construída socialmente, pois este só o é a partir do olhar de determinadas regras sociais que vão definir o que é normal.

A imposição de regras tem suas premissas: primeiro, é um empreendimento no qual alguém deve tomar a inciativa de punir o culpado; segundo, a infração é tornada pública, alguém delata; terceiro, as pessoas são estimuladas a "dedurarem" o comportamento infrator; por último, o tipo de interesse pessoal varia conforme a complexidade da situação em que a imposição tem lugar. Ou seja, quanto maior o número de grupos rivais, mais complexa é a imposição de regras porque há mais interesses em jogo, o que leva as pessoas a converterem valores em regras, o que as classifica em empreendedores morais: criadores de regras e impositores de regras. Para que exista o desviante, primeiro deve haver a regra que o define como tal e esta só existe se algum empreendedor moral a cria e a impõe (BECKER, 2008).

A Teoria da Rotulação Reconsiderada procura explicar como as pessoas que cometem atos desviantes passam a fazê-lo e por que elas o fazem. 0 ato de rotular é prática do empreendedor moral, mas não explica o comportamento desviante, que não acontece simplesmente porque alguém assim o considera e sim como aprendizado resultante da interação social. Mead (1934) e Blumer (1969) contribuem com o entendimento de que este não é um estudo da sociedade, mas da ação coletiva, porque as pessoas agem juntas: "Elas fazem o que fazem com um olho no que outras fizeram, estão fazendo e podem fazer no futuro" (BECKER, 2008, p. 183). Prática do ajustamento e acomodação como entendimento de que as pessoas levam em consideração o que está acontecendo e o que vai acontecer para decidir o que farão, ou seja, o ato desviante não é ação isolada, mas uma reação complexa de atos envolvendo outros, o que nos leva a uma abordagem interacionista do desvio. De acordo com Goffman (1985), o meio social pode ser considerado um espetáculo teatral no qual os indivíduos são considerados atores interpretando papéis, sejam verdadeiros ou falsos. As roupas podem ser consideradas importantes ferramentas auxiliares na performance desses papéis devido a sua capacidade de comunicar.

\section{0 estudo}

0 ponto de partida desse estudo é o uso da saia por homens, o que pode ser visto no contexto sociocultural brasileiro como um comportamento desviante, pois infringe a regra da saia como de pertencimento ao feminino.

O objetivo desse estudo é fazer uma análise foucaultiana das narrativas desse consumidor desviante utilizando como apoio o estudo de sociologia do desvio de Becker (2008) que fala das regras sociais que definem o que é o comportamento apropriado e o que é o comportamento das pessoas que não vivem de acordo com essas regras, sendo encaradas como outsiders, desviantes ou marginais para identificar o nosso corpus de pesquisa. Becker (2008) observa que a transgressão das regras é a essência do comportamento e existem vários tipos de regras: a lei que usa o poder de polícia do Estado para se impor e outras que são informais e estabelecidas pela tradição.

Seguiremos os questionamentos de Becker (2008) para entender o comportamento de homens que usam saia, pois eles são os outsiders - aqueles que se desviam das regras de 
grupo -, o que nos ajudou a elaborar as seguintes perguntas de pesquisa iniciais: por que fazem isso? Como podemos explicar sua transgressão das regras? O que há neles que os leva a fazer coisas proibidas?

Entendendo que diferentes grupos consideram diferentes coisas como desviantes, este estudo considera como contexto sociocultural a cidade do Rio de Janeiro e parte da constatação de que, nessa cidade, o homem de saia é considerado desviante porque sofre processos de julgamento na visão de senso comum. 0 desvio é socialmente construído pois é resultado da reação do outro ao ato de uma pessoa. 0 que o grupo de desviantes tem em comum e o que os leva a serem visto como tal é partilharem o rótulo e a experiência de serem rotulados como desviantes. Portanto, às perguntas iniciais cabe complementar com as seguintes perguntas: como eles relatam o processo pelo qual foram considerados desviantes? Qual é a reação do desviante a esse julgamento?

O nosso objeto de pesquisa é o desviante puro, pois ele comete o "ato infrator" em público e é percebido pelos demais grupos como desviante, existe o julgamento social. A criação e a imposição de regras levam às punições que podem acontecer, no caso, desde o constrangimento público até espancamento e morte.

A Teoria da Rotulação Reconsiderada de Becker estabelece relações com o interacionismo simbólico, o que leva à reflexão dos estudos de Goffman $(1985,1988)$, Mead $(1934)$ e Blumer (1969), propondo uma abordagem interacionista do desvio, definindo-o como uma imposição de definições - de situações, atos e pessoas - por quem é poderoso ou legitimado o bastante para tanto.

Thompson, Pollio e Locander (1994) mostram que tanto a interpretação dos significados pessoais quanto a compreensão reflexiva do eu, e tanto a interpretação quanto a compreensão de um texto dependem da história pessoal do consumidor para serem realizadas, resultando na atribuição de significados expressos na linguagem desse consumidor, o que apoia o uso nesse estudo das técnicas de "história de vida" e "projetiva" junto às entrevistas narrativas. As entrevistas narrativas consideram as histórias a forma mais interessante de relato de experiências e significados. As histórias é que trazem o sentido da vida (SHANKAR; ELLIOT; GOULDING, 2001).

Os entrevistados foram identificados em três eventos com proposta de comportamento desviante que aconteceram na cidade do Rio de Janeiro: Pepsi Twist Land com shows dos Caramelows, Liniker, Banda Uó, Johnny Hooker, Caio Prado e As Bahias e a Cozinha Mineira; show no Circo Voador com As Bahias e a Cozinha Mineira, com participação de Pabllo Vittar e Mc Linn da Quebrada; e Madrugada no Centro no CCBB com show de Os Não Recomendados e Karina Buhr. Algumas entrevistas aconteceram em encontros casuais em locais públicos fora desse circuito. Todos os entrevistados estavam usando saia quando foram encontrados na rua, menos os três que foram indicações. Todos são moradores do Rio de Janeiro. As observações e entrevistas aconteceram de 7 de fevereiro a 14 de junho de 2017. Foram realizadas 20 entrevistas em profundidade. As entrevistas tiveram duração variando de 90 minutos, transcritos em 40 páginas, a 40 minutos, transcritos em 13 páginas, totalizando 21 horas e 13 minutos de gravação transcritas em 465 páginas. 0 quadro 1 mostra um breve perfil dos entrevistados de 18 a 41 anos com diversas orientações sexuais, 
estados civis e ocupações. Cabe observar que a orientação sexual não constava do roteiro aberto, mas foi uma declaração espontânea e importante para a descrição do perfil.

\begin{tabular}{|c|c|c|c|c|c|}
\hline ENTREVISTADO & IDADE & OCUPAÇÃO & ESTADO CIVIL & $\begin{array}{l}\text { ORIENTAÇÃOO } \\
\text { SEXUAL }\end{array}$ & LOCAL \\
\hline $\mathrm{A} 1$ & 33 & $\begin{array}{l}\text { Ator/vendedor na Green } \\
\text { People }\end{array}$ & $\begin{array}{l}\text { Solteiro sem } \\
\text { namorado }\end{array}$ & Homossexual & Pespsi Twist Land \\
\hline $\mathrm{A} 2$ & 23 & Designer de moda & $\begin{array}{l}\text { Mora com o } \\
\text { namorado }\end{array}$ & Homossexual & Loja Dona Coisa \\
\hline B & 31 & $\begin{array}{l}\text { Professor de ciências e } \\
\text { biologia do } 6^{\circ} \text { ano ao ensino } \\
\text { médio; doutorando em } \\
\text { história e filosofia da ciência }\end{array}$ & $\begin{array}{l}\text { Mora com a } \\
\text { namorada }\end{array}$ & Heterossexual & $\begin{array}{c}\text { As Bahias e a } \\
\text { Cozinha Mineira }\end{array}$ \\
\hline $\mathrm{C} 1$ & 37 & Ator; hostess airbnb & $\begin{array}{l}\text { Mora com o } \\
\text { namorado }\end{array}$ & Homossexual & $\begin{array}{l}\text { Madrugada no } \\
\text { Centro }\end{array}$ \\
\hline $\mathrm{C} 2$ & 37 & Técnico judiciário & $\begin{array}{l}\text { Namorado } \\
\text { quase casado. }\end{array}$ & Homossexual & Pepsi Twist Land \\
\hline C3 & 38 & Arquiteto & Solteiro & Homossexual & $\begin{array}{l}\text { As Bahias e a } \\
\text { Cozinha Mineira }\end{array}$ \\
\hline D1 & 31 & $\begin{array}{l}\text { Biólogo; pós-doutorando } \\
\text { em planejamento energético } \\
\text { ambiental }\end{array}$ & Namorando & Heterossexual & $\begin{array}{l}\text { Indicação do } \\
\text { entrevistado B }\end{array}$ \\
\hline D2 & 23 & Produtor de moda & Solteiro & Homossexual & $\begin{array}{l}\text { Indicação de } \\
\text { conhecido }\end{array}$ \\
\hline D3 & 19 & Estudante de moda & Solteiro & Homossexual & $\begin{array}{l}\text { Indicação de } \\
\text { conhecido }\end{array}$ \\
\hline $\mathrm{F} 1$ & 26 & Assistente de estilo & Namorando & Homossexual & $\begin{array}{l}\text { Indicação do } \\
\text { entrevistado G }\end{array}$ \\
\hline $\mathrm{F} 2$ & - & $\begin{array}{l}\text { Estudante de jornalismo; } \\
\text { supervisor de comunicação }\end{array}$ & Namorando & Homossexual & Pepsi Twist Land \\
\hline G1 & & Escritor; produtor cultural & $\begin{array}{l}\text { Mora com a } \\
\text { namorada }\end{array}$ & Heterossexual & Espaço Carandaí \\
\hline G2 & 41 & Estilista & Casado & Heterossexual & $\begin{array}{l}\text { Circo Voador - } \\
\text { festa do Bloco } \\
\text { Amigos da Onça }\end{array}$ \\
\hline $\mathrm{H}$ & 22 & $\begin{array}{l}\text { Estudante de atuação cênica; } \\
\text { ator }\end{array}$ & Solteiro & Homossexual & Pepsi Twist Land \\
\hline $\mathrm{J}$ & 22 & Estudante de administração & $\begin{array}{c}\text { Mora com o } \\
\text { namorado }\end{array}$ & Homossexual & $\begin{array}{l}\text { Madrugada no } \\
\text { Centro }\end{array}$ \\
\hline L1 & 18 & Estudante de moda; drag & Solteiro & Homossexual & $\begin{array}{l}\text { As Bahias e a } \\
\text { Cozinha Mineira }\end{array}$ \\
\hline L2 & 38 & $\begin{array}{l}\text { Ex-executivo; trabalha com } \\
\text { gastronomia }\end{array}$ & $\begin{array}{l}\text { Divorciado } \\
\text { duas vezes. } \\
\text { Namorando. }\end{array}$ & Heterossexual & Shopping da Gávea \\
\hline L3 & 26 & $\begin{array}{l}\text { Psicólogo; mestre em teoria } \\
\text { psicanalitica }\end{array}$ & Solteiro & Homossexual & $\begin{array}{l}\text { Madrugada no } \\
\text { Centro }\end{array}$ \\
\hline L4 & 28 & Ator; produtor; professor & - & Homossexual & Pepsi Twist Land \\
\hline$P$ & - & $\begin{array}{l}\text { Designer de moda; } \\
\text { empresário }\end{array}$ & Solteiro & Homossexual & Indicação de amigo \\
\hline
\end{tabular}

FONTE: os autores, 2017. 
Para a análise das imagens captadas durante as abordagens para entrevista adotou-se a proposta de análise de imagem parada de moda de Maciel e Miranda (2009). Assim, esse método parte de critérios pré-estabelecidos (quadro 2) de observação para identificar semelhanças e, em seguida, interpretá-las.

\section{QUADRO 2 - CRITÉRIOS DE ANÁLISE DA IMAGEM DE MODA}

\begin{tabular}{|l|l|}
\hline \multicolumn{1}{|c|}{ CRITÉRIOS } & DESCRIÇÃO \\
\hline 1 - Forma & Pontos em comum na construção do traje - modelagem, comprimento, volumes das peças em análise. \\
\hline 2 - Cor & Pontos em comum na predominância das cores e sua composição na peça ou no traje. \\
\hline 3 - Materiais & $\begin{array}{l}\text { Pontos em comum nos materiais utilizados para confecção das peças, tais como tecidos e aviamentos, e } \\
\text { pontos em comum nos materiais utilizados para confecção de acessórios. }\end{array}$ \\
\hline $4-$ Composição & $\begin{array}{l}\text { Pontos em comum na forma de compor as peças no traje, e pontos em comum entre o uso de acessórios, } \\
\text { mesmo que atualizados ou substituídos por outros símbolos de composição do traje. }\end{array}$ \\
\hline 5 - Gestual & Pontos em comum na forma de usar e de se comportar no momento da captação da imagem. \\
\hline
\end{tabular}

FONTE: Maciel e Miranda (2009).

\section{Principais achados}

Historicamente, já tivemos a "invasão do guarda-roupa masculino" pelas mulheres, o que teve seu momento mais pungente relacionado às lutas feministas por igualdades de direitos e a busca dos significados de poder e força traduzidos pelo uso de ternos, calças, ombreiras, gravatas (LURIE, 1997). No uso da saia por homens o que se percebe é o contrário; na saia os homens se fragilizam, pois as associações ao feminino são de fraqueza e submissão. Nessa inversão de valores tanto das mulheres feministas de outrora como dos homens desviantes de agora encontramos uma busca em comum: a liberdade de ação e o uso do discurso da moda como ato político de quebra de convenções sociais, a busca por uma utopia social, uma sociedade que não julga o outro por uma aparência convencionada e que permite a livre escolha. A ação consciente destes indivíduos enquanto transgressores da regra está em difundir um novo comportamento que busca a sua massificação e, por conseguinte, a sua normalização. 0 que está em jogo aqui não é a aparência, mas a estética que é a reação do outro sobre esta aparência, o que nos leva a falar do discurso da moda sob outros parâmetros.

\section{O proibido, o coletivo e a aceitação: o cuidado de si}

Ser modelo de comportamento como uma forma de se libertar e de libertar o outro, como uma cadeia de continuidade buscando a normalização do comportamento. 0 estranhamento vem da não exposição ao fato e quando este passa a ser corriqueiro deixa de ser anormal e a massificação normaliza a ação. 
Hoje a questão de usar a saia, batom, cabelo branco, de fazer o que quero é muito uma questão de resistência, de ser o que tenho vontade. E o que falei de não ser só por mim, mas alguém me ver na rua e alguém que conheço falar: "Eu também posso fazer porque ele faz, não sou só eu". Eu penso muito nisso, tenho muito esse pensamento, nesse coletivo. Como fui me reconhecendo em outras pessoas... e de ser o objeto reconhecido pelos outros... Alguém que as pessoas possam reconhecer. ${ }^{4}$

Em Chevitarese, Fonseca e Trajano (2017) encontramos a relação entre a dinâmica saber-poder e as relações que produzem formas de subjetividade e que estabelecem identidades criando campos de ação possíveis pela demarcação de padrões de normalidade.

0 transgressor busca locais onde é possível transgredir ainda apresentando comportamento de "gueto" por medo das reações dos empreendedores morais, conforme Becker (2008), que tanto são seus criadores quanto seus impositores, e que se sentem livres para punir o infrator da regra.

Você pode se vestir da forma que você quiser. Circo Voador, Lapa, Praça Tiradentes que tem um bar que está superlegal, bar do Nanam. Você tem que ir! Então dá o Rio de Janeiro inteiro. É um bar coletivo também, gosto mais das coisas mais coletivas. Que dá todo tipo de gente, final de festa, vai o pessoal do casamento que está de terno, por exemplo, não posso ir de saia num casamento ou de chinelo de dedo, tenho que me adaptar, vou ao casamento de terno, mas no bar do Nanam vai estar o final de festa de casamento, vai estar o final de festa do pessoal da Lapa... Coletivo. ${ }^{5}$

Você sai de casa pra se divertir e tem que ficar batendo boca porque você está de saia, de batom... por que não sei quem esbarrou em você e jogou você longe! Não gosto, então não vou em lugares assim. Gosto de lugares que são mais democráticos e tolerantes a todas as diferenças, à pluralidade, seja lá o que isso significa e isso significa muita coisa. Prefiro lugares assim, acho que Rival e Rivalzinho conjugam nisso, sincretizam... ${ }^{6}$

O discurso da liberdade inclui o outro e nessa ética-estética da existência está a "prática de liberdade" compreendida como condição de possibilidade para a criação de novas formas de existência (CHEVITARESE; FONSECA; TRAJANO, 2017). Fica claro aqui o entendimento de que o sujeito sofre a ação do poder, mas também o exerce por meio de seus discursos, incluso a frase visual.

\footnotetext{
4 Entrevista concedida por F2. Entrevista 11. [27 abr. 2017]. Entrevistadora: Ana Paula de Miranda. Rio de Janeiro, 2017. Arquivo.mp3 (50 min.).

${ }^{5}$ Entrevista concedida por C3. Entrevista 7. [14 fev. 2017]. Entrevistadora: Ana Paula de Miranda. Rio de Janeiro, 2017. Arquivo.mp3 (45 min.).

${ }^{6}$ Entrevista concedida por L3. Entrevista 9. [3 abr. 2017]. Entrevistadora: Ana Paula de Miranda. Rio de Janeiro, 2017. Arquivo.mp3 (65 min.).
} 
Não acho que todo mundo tem que usar saia ou tenha que ser diferente, faz o que você quiser, desde que eu possa usar o que eu quiser também e a gente vai se respeitar. E não vai ter lugar pra eu usar a saia, não vai ter lugar para... Acho que a gente ia ser muito mais feliz assim, os encontros iam ser melhores. As pessoas legais que ainda tem aí, que não se permitem, estão com a cabeça fechada pra muita coisa. ${ }^{7}$

A história de que a mãe dele usava como referência para puni-lo "se você fizer isso você vai ser igual ao filho da Dayse", o filho da Dayse era uma figura mitológica para ele, que ele não conheceu, era tipo... No subúrbio tinha muito isso "o filho da fulana é assim e assado, você vai ficar igual a ele". 0 subúrbio é muito amigável, muito cordial, mas muito cruel também porque as pessoas interferem umas nas vidas das outras e quando tira um para ser julgado, essa pessoa vai ser julgada e vai ser crucificada, execrada, como o filho da Dayse, por exemplo. Ele usa como parâmetro de moralidade. Você pode chegar até aqui, passou daqui você é o filho da Dayse, então para ali. E no final ele fala: "O filho da Dayse deve ser um cara super legal"."

Os empreendedores morais: transgressão e defesa

\section{Fica claro que só é possível a ação desviante porque existe o empreendedor moral e, ao mesmo tempo, o objetivo da ação desviante é mudar o pensamento conservador que começa com a imposição que nega a liberdade de escolha.}

A primeira vez que eu usei saia, que foi a cinza, peguei ônibus do Leblon para Botafogo, ninguém mexeu comigo, estava de fone, música baixa, fiquei observando todo mundo, querendo ouvir se ia ouvir gracinhas ou alguma crítica ou alguma risada, zero. Ônibus cheio, não tão cheio, mas cheio, andei na rua, a galera olha, mas tipo é olhar provinciano, crítico, medroso, aquele que fica da janela rindo, mas também não joga ovo porque eu tenho cara de ogro, tatuado, largo, que posso enfiar porrada. Só por isso. Se eu fosse franzino ou com cara de bundão... ${ }^{9}$

Como uma vez... eu já saia de saia, fui no bar comprar um pão de queijo, o rapaz: "Sai fora!" Não falou diretamente para mim, mas falou ao ar. E eu com carão "E aí?" A partir do momento que direcionar a palavra, ou o olhar, vou rebater, mas enquanto isso deixa ele falar, não está me atingindo, tem que mostrar que isso é

\footnotetext{
7 Entrevista concedida por H. Entrevista 5. [13 fev. 2017]. Entrevistadora: Ana Paula de Miranda. Rio de Janeiro, 2017. Arquivo.mp3 (56 min.).

8 Entrevista concedida por C2 Entrevista 6. [13 fev. 2017]. Entrevistadora: Ana Paula de Miranda. Rio de Janeiro, 2017. Arquivo.mp3 (78 min.).

9 Entrevista concedida por L2. Entrevista 13. [28 abr. 2017]. Entrevistadora: Ana Paula de Miranda. Rio de Janeiro, 2017. Arquivo. $\mathrm{mp3}$ (90 min.).
} 
só uma saia, é só uma peça, tem que aceitar. 0 que a gente não pode aceitar é violência, ruindade, falta de caráter, por que uma peça de roupa é apenas um pano. ${ }^{10}$

A ressignificação da ética-estética repete tensões de poder em "não se mete comigo porque eu posso enfiar porrada" e "faço carão", ficando claro que a saia simbólica do feminino tem que ser revestida com características próprias do masculino para ser respeitada, reproduzindo assim a dinâmica de violência social.

\section{Significação da saia e processo de "desconstrução da normalização"}

Analisando essa questão, vemos que tanto para o hetero quanto para o homossexual usar a saia passa por assumir características de outro gênero como se "abrir mão" da masculinidade fosse o maior dos pecados. Segundo Chevitarese, Fonseca e Trajano (2017), é dessa relação hierárquica entre homens e mulheres que estamos falando aqui, e a significação da saia seria a forma de "desconstruir a normalização" dessa relação e questionar essa hierarquia.

O kilt porque entrou como parte da minha vida. Eu acho muito clássico de verdade. No início quando comecei a usar eu tinha muito olhar enviesado, muita gente me olhava torto. Essa coisa de "estou usando kilt, uma saia" e implica uma certa feminilidade em mim. Daí sou veado. E se eu for? Não sou, mas e se eu for qual o problema? Sempre me incomodou o julgamento alheio e às vezes você não está a fim de andar na rua encarando a sociedade te olhando torto. Vai pelo caminho mais fácil mas eu acho que a gente tem progredido como sociedade e cada vez mais ao andar de kilt na rua percebo menos pessoas me olhando ou eu estou me importando menos... Pode ser também. ${ }^{11}$

Discursos de moda como discursos que estabelecem relações de poder

A saia é o texto mais eloquente sobre a liberdade desse homem que não quer estar preso ao que se convencionou como natural e imutável, como nos falam Chevitarese, Fonseca e Trajano (2017) ao tratar da falta de liberdade tanto de homens quanto de mulheres sobre o seu modo de ser.

\footnotetext{
${ }^{10}$ Entrevista concedida por F1. Entrevista 14. [31 mai. 2017]. Entrevistadora: Ana Paula de Miranda. Rio de Janeiro, 2017. Arquivo.mp3 (90 min.).

${ }^{11}$ Entrevista concedida por B. Entrevista 12. [27 abr. 2017]. Entrevistadora: Ana Paula de Miranda. Rio de Janeiro, 2017. Arquivo.mp3 (90 min.).
} 
Esse rapaz que é hetero, ele veste a saia por quê? Por que não vestir a saia? Quer usar uma saia! Não depende da orientação sexual. Eu acho que a vida é isso: quanto mais você se autoconhece, que é esse exercício do autoconhecimento que acho muito importante... que está na psicologia, na filosofia, você também vai se desamarrando dessas amarras e desse emaranhado de coisas que possam te angustiar. ${ }^{12}$

Tem uma frase que até tem no meu Instagram, é assim "coisas unissex: todas" todas, tudo é unissex, não existe. Eu poderia estar dentro desse look que você está usando e você poderia estar dentro do look que eu estou usando. Se as pessoas pudessem exercitar isso... Nossa! 0 mundo ia estar tão diferente... ${ }^{13}$

A relação dos achados de pesquisa com a filosofia de Foucault está nessa atitude de insubmissão ao mundo, ou seja, o uso da saia por estes homens é o uso do discurso da moda como discurso que problematiza relações de poder contra as formas impostas de subjetividade. Mas, como isso é materializado nessa saia de homem?

\section{Análise da imagem de moda}

Foram analisadas 20 imagens, das quais três delas serão utilizadas para tratar do discurso visual e apresentar os elementos constitutivos dessa "saia de homem". As associações que são feitas à saia enquanto pertencente ao feminino sofrem negociação simbólica com os demais elementos, "masculinizando" a peça.

FIGURA 1 - O GUERREIRO

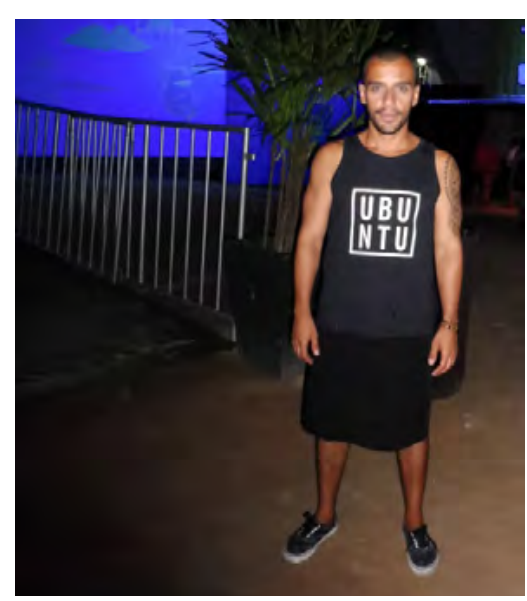

FONTE: MIRANDA, Ana Paula. 0 Guerreiro. 2017. 1 fotografia

\footnotetext{
${ }^{12}$ Entrevista concedida por C1. Entrevista10. [27 abr. 2017]. Entrevistadora: Ana Paula de Miranda. Rio de Janeiro, 2017. Arquivo.mp3 (75 min.).

${ }^{13}$ Entrevista concedida por P. Entrevista 20. [14 jun. 2017]. Entrevistadora: Ana Paula de Miranda. Rio de Janeiro, 2017. Arquivo.mp3 (81 min.).
} 
QUADRO 3 - ANÁLISE DA FIGURA 1

\begin{tabular}{|c|c|c|}
\hline & DENOTAÇÃO & CONOTAÇÃO \\
\hline FORMA & $\begin{array}{l}\text { Camiseta reta sem mangas, solta do corpo, saia reta abaixo } \\
\text { do joelho. }\end{array}$ & $\begin{array}{l}\text { Simplicidade. A cintura não é marcada, a ausência de } \\
\text { mangas mostra os músculos e traz os significados de força. }\end{array}$ \\
\hline COR & Preto total com dizeres da camiseta em branco. & $\begin{array}{l}\text { Seriedade que remete à masculinidade. Ubuntu é } \\
\text { uma filosofia africana que desenvolve o conceito } \\
\text { de humanidade, respeito e solidariedade, trata da } \\
\text { importância das alianças e do relacionamento das } \\
\text { pessoas umas com as outras. }\end{array}$ \\
\hline MATERIAL & "Malha" e "tecido de alfaiataria" & $\begin{array}{l}\text { A malha é simplicidade e conforto. A alfaiataria rigidez, } \\
\text { elegância. }\end{array}$ \\
\hline COMPOSIÇÃO & Modelagem reta sem detalhes. Tênis esportivo. & Austeridade. \\
\hline GESTUAL & $\begin{array}{l}\text { Braços soltos, pernas abertas, cabeça erguida, olhar fixo e } \\
\text { expressão séria, quase desafiadora. }\end{array}$ & Tranquilidade e serenidade. \\
\hline
\end{tabular}

FONTE: os autores, 2017.

A imagem remete à figura do guerreiro. Ele tem um propósito, uma luta, a saia é sua bandeira e a sua atitude é de quem leva a sério esse compromisso. Nesta saia o texto fala de quem está desafiando a normalização e usando elementos do masculino para contagiar essa saia e quebrar a regra simbólica do elemento feminino enquanto residência da fragilidade.

FIGURA 2 - 0 IRREVERENTE

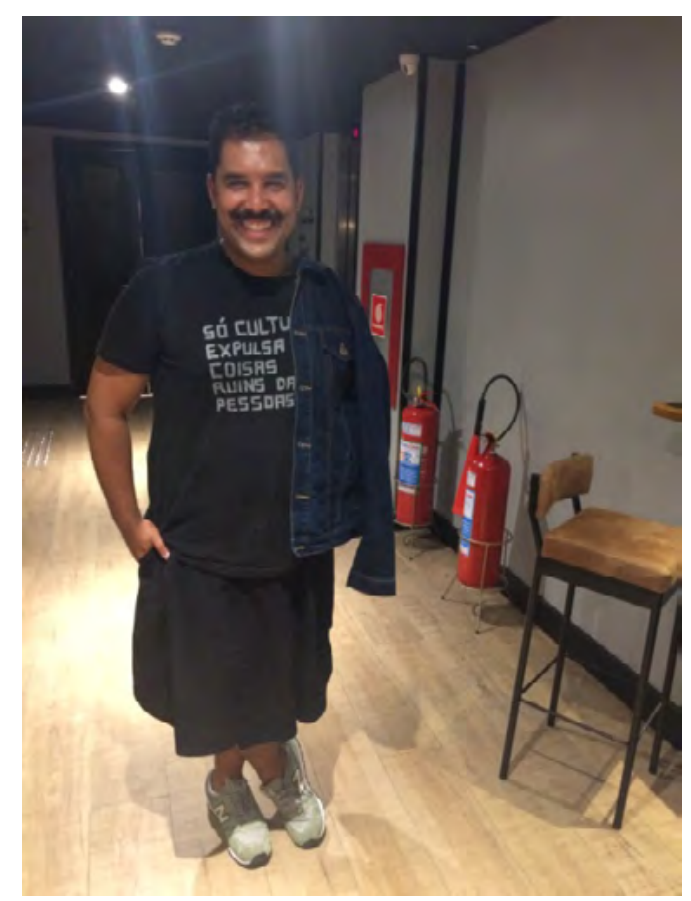

FONTE: MIRANDA, Ana Paula. O Irreverente. 2017. 1 fotografia 
QUADRO 4 - ANÁLISE DA FIGURA 2

\begin{tabular}{|c|c|c|}
\hline & DENOTAÇÃO & CONOTAÇÃO \\
\hline FORMA & $\begin{array}{l}\text { Camiseta reta com mangas, solta do corpo, saia reta } \\
\text { com drapeado e comprimento quase no tornozelo. } \\
\text { Jaqueta esportiva. }\end{array}$ & $\begin{array}{l}\text { Simplicidade. Os cortes retos trazem os significados de } \\
\text { conforto. O equilíbrio das formas conota elegância e } \\
\text { senso estético. }\end{array}$ \\
\hline COR & $\begin{array}{l}\text { Preto total com dizeres da camiseta em branco. Blue } \\
\text { jeans na jaqueta. }\end{array}$ & $\begin{array}{l}\text { A seriedade do preto é quebrada pela jovialidade do } \\
\text { blue jeans, que remete à alegria e simpatia. Os dizeres } \\
\text { "Só cultura expulsa coisas ruins das pessoas" explicita o } \\
\text { compromisso com o conhecimento como instrumento } \\
\text { de transformação. }\end{array}$ \\
\hline MATERIAL & “"Malha”, “alfaiataria”, “jeans”. & $\begin{array}{l}\text { Simplicidade, conforto e elegância com a rigidez da } \\
\text { alfaiataria sendo quebrada pela jovialidade do jeans e } \\
\text { pelo drapeado da forma que a suaviza. }\end{array}$ \\
\hline COMPOSIÇÃOO & $\begin{array}{l}\text { Modelagem reta e solta do corpo que vai ser "ajustada" } \\
\text { apenas quando do uso da jaqueta. Tênis esportivo. }\end{array}$ & $\begin{array}{l}\text { Serenidade, tranquilidade, senso estético, elegância e } \\
\text { refinamento. }\end{array}$ \\
\hline GESTUAL & $\begin{array}{l}\text { Mãos nos bolsos, pernas cruzadas na altura dos } \\
\text { tornozelos, jaqueta sobre um dos ombros, sorriso largo. }\end{array}$ & Despojamento, jovialidade, alegria. \\
\hline
\end{tabular}

FONTE: os autores, 2017.

A imagem remete à figura da irreverência, que é a contestação de bom humor. A negociação simbólica com o masculino está presente na cor e na forma, mas a ousadia está presente nos elementos do drapeado, que é do feminino, e do jeans, que é da jovialidade. A saia é bandeira, mas a criatividade dá o tom do discurso misturando elementos que, ao fazerem piada com a situação, ridicularizam-na e, assim sendo, expõem ao ridículo quem se choca ou se ofende, ou seja, o empreendedor moral.

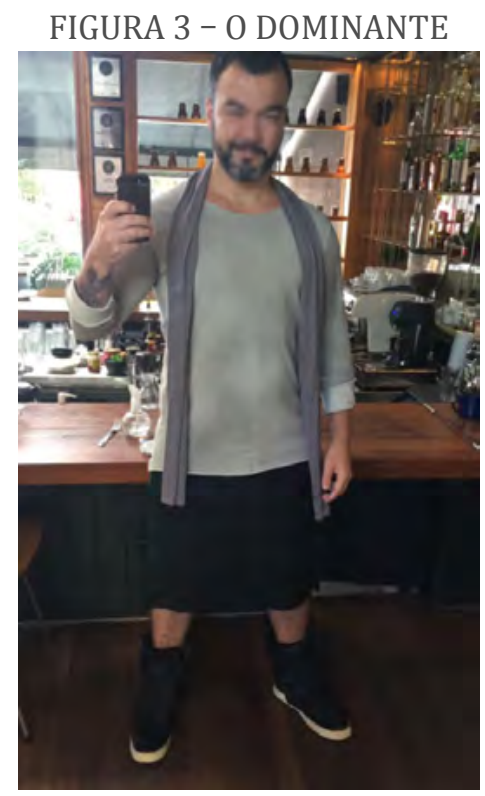

FONTE: O DOMINANTE. Autoretrato do entrevistado. 2017. 1 fotografia 
QUADRO 5 - ANÁLISE DA FIGURA 3

\begin{tabular}{|c|c|c|}
\hline & DENOTAÇÃOO & CONOTAÇÃO \\
\hline FORMA & $\begin{array}{l}\text { Blusa e saia retas ajustadas ao corpo, mangas } \\
\text { compridas, echarpe solta sobre os ombros. }\end{array}$ & $\begin{array}{l}\text { Simplicidade. } 0 \text { encontro do reto com o ajustado e o } \\
\text { decote um pouco mais revelador fala de sensualidade e do } \\
\text { conforto com o próprio corpo. A echarpe conota elegância } \\
\text { e senso estético. }\end{array}$ \\
\hline COR & Preto, cinza, cinza-azulado. & Seriedade, sobriedade. \\
\hline MATERIAL & "Malha" e "alfaiataria". & $\begin{array}{l}\text { Conforto, simplicidade, austeridade, elegância, que são } \\
\text { quebradas pela sensualidade do decote e das formas mais } \\
\text { ajustadas e o despojamento da echarpe solta sobre os ombros. }\end{array}$ \\
\hline COMPOSIÇÃOO & $\begin{array}{l}\text { Modelagem reta sem detalhes. Echarpe despojada } \\
\text { sem ser afetada e tênis pesado que lembra um } \\
\text { coturno. }\end{array}$ & $\begin{array}{l}\text { Serenidade, tranquilidade, senso estético, elegância e } \\
\text { refinamento. } 0 \text { tênis dá um tom de poder, de força ao look } \\
\text { tanto quanto a echarpe fala de uma elegância blasé. }\end{array}$ \\
\hline GESTUAL & $\begin{array}{l}\text { Braços soltos, pernas abertas, sorriso de lado que } \\
\text { desafia e seduz. }\end{array}$ & $\begin{array}{l}\text { Sensualidade do macho alfa totalmente à vontade consigo e } \\
\text { com seu corpo. }\end{array}$ \\
\hline
\end{tabular}

FONTE: os autores, 2017.

A imagem remete ao dominante. A liberdade de escolha na construção do look é revelada pelo uso de elementos do masculino e do feminino de forma híbrida, equilibrando a combinação sem deixar de ressaltar o masculino que se sobrepõe. Neste visual fica claro o domínio dos elementos masculinos sendo a saia um texto que fala da absoluta segurança do indivíduo consigo mesmo, demonstrando que este transcende o julgamento do outro.

\section{Considerações finais: o nível mítico}

O mito é o símbolo que representa uma hierarquia de valores éticos e/ou estéticos em narrativas e/ou imagens. 0 discurso mítico é da transcendência.

0 desviante social, aqui identificado por escolher um desvio de comportamento de moda, neste caso em estudo é o "homem de saia", que tem esse comportamento de consumo porque se considera responsável por si e esta responsabilidade tem que refletir a responsabilidade com o outro. A relação com Foucault e as práticas de "cuidado de si" ficam claras: a prática de reinvenção de si mesmo como forma de resistência aos padrões de normalização social são formas de resistência dos indivíduos que buscam a ressignificação da liberdade. A transgressão às regras é a forma de falar desse desconforto com o estabelecido e tornar o seu desconforto no desconforto alheio. Esse é o ponto a partir do qual ele passa a ser considerado como desviante e a reação dele a esse julgamento está no conceito de resistência; enquanto houver a reação negativa ao comportamento existe o desvio, e se o tempo de resistência perdurar ao tempo das punições chegará o tempo em que não existirá mais o desvio, e este é o objetivo do desviante.

A "saia de homem" como materialidade dessa resistência mostra a negociação simbólica que busca o equilíbrio entre o feminino e o masculino, mas que ainda usa elementos masculinos como armadura e proteção. 0 preto, o reto, o pesado se sobrepõem e acrescentam o predicado ao sujeito saia nessa frase visual, possibilitando a transição onde o colorido, o babado, o suave forneceriam um discurso de fragilidade que os empreendedores sociais não perdoariam. 


\section{Referências}

BECKER, Howard S. Outsiders: estudos de sociologia do desvio. Tradução Maria Luiza X. de A. Borges. Rio de Janeiro: Zahar, 2008.

BLUMER, Herbert. Fashion: from class differentiation to collective selection. Sociological Quarterly, v. 10, n. 3, p. 275-291, 1969.

CHEVITARESE, Leandro; FONSECA, Vanessa; TRAJANO, Lindalva. Desconstrução de identidade de gênero: uma leitura foucaultiana sobre as formas de resistência como práticas de liberdade. Revista Latino-Americana do Colégio Internacional de Filosofia. n. 2, p. 87-110, 2017. Disponível em: http://www.revistalatinoamericana-ciph.org/wp-content/ uploads/2017/07/RLCIF-2-Deconstruçao.pdf. Acesso em: 18 jul. 2019.

FOUCAULT, Michel. Surveiller et punir: naissance de la prison. Paris: Gallimard, 1975.

FOUCAULT, Michel. Histoire de la sexualité I: la volonté de savoir. Paris: Gallimard, 1977.

FOUCAULT, Michel. Le sujet et le pouvoir. In: Dits et écrits. Vol. IV. Paris: Gallimard, 1994a.

FOUCAULT, Michel. L'éthique du souci de soi comme pratique de la liberté. In: Dits et écrits. Vol. IV. Paris: Gallimard,1994b.

FOUCAULT, Michel. Pouvoir et savoir. In: Dits et écrits. Vol. III. Paris: Gallimard, 1994c.

FOUCAULT, Michel. L'herméneutique du sujet. Cours au Collège de France (1981-1982). Paris: Seuil, 2001.

GOFFMAN, Erving. A representação do eu na vida cotidiana. Tradução Maria Célia Santos Raposo. Petrópolis: Vozes, 1985.

GOFFMAN, Erving. Estigma: notas sobre a manipulação da identidade deteriorada. Tradução Márcia Bandeira de Mello Leite Nunes. Rio de Janeiro: Ed. LTC, 1988.

LURIE, Allison. A linguagem das roupas. Tradução Ana Luiza Dantas Borges. Rio de Janeiro: Rocco, 1997.

MACIEL, Eduardo J. C.; MIRANDA, Ana Paula de. DNA da Imagem de Moda. In: COLÓQUIO NACIONAL DE MODA, 5., 2009. Recife. Anais [...]. São Paulo: Abepem, 2009. Disponível em: http://www.coloquiomoda.com.br/anais/Coloquio\%20de\%20Moda\%20-\%202009/ Consumo-de-Moda/. Acesso em: 2 jun. 2017. 
MEAD, George H. Mind, self and society: from the standpoint of a social behaviorist. 1. ed. Chicago: The University of Chicago Press,1934.

SHANKAR, Avi; ELLIOT, Richard; GOULDING, Christina. Understanding Consumption: Contributions from a Narrative Perspective. Journal of Marketing Management, v. 17, n. 3-4, p. 429-453, 2001. Disponível em: https://www.tandfonline.com/doi/ abs/10.1362/0267257012652096. Acesso em: 18 jul. 2019.

SIMMEL, Georg. Fashion. International Quarterly, p. 130-155, 1904.

THOMPSON, Craig J.; POLLIO, Howard R.; LOCANDER, William. B. The spoken and the unspoken: a hermeneutic approach to understanding the cultural viewpoints that underlie consumers' expressed meanings. Journal of Consumer Research, v. 21, n. 3, p. 432-452, December 1994. Disponível em: https://www.jstor.org/stable/2489684. Acesso em: 18 jul. 2019.

VELHO, Gilberto. Accusations, family mobility and deviant behavior. Social Problems, Buffalo, v. 23, n. 3, p. 268-275, Feb. 1976. Disponível em: https://www.jstor.org/ stable/799773. Acesso em: 18 jul. 2019. 